Original Article

\title{
Buccolingual Inclination Effects of Self-Ligating and Conventional Premolar Brackets: A Cone Beam Computed Tomography Study
}

\author{
Sabahat Yazıcıoğlu (iD, A. Alper Öz (iD, A. Zeynep Öz (D), Nursel Arıcı (D), Mete Özer (D), Selim Arıcı (DD
}

Department of Orthodontics, Ondokuz Mayıs University School of Dentistry, Samsun, Turkey

Cite this article as: Yazıcıoğlu S, Öz AA, Öz AZ, Arıcı N, Özer M, Arıcı S. Buccolingual Inclination Effects of Self-Ligating and Conventional Premolar Brackets: A Cone Beam Computed Tomography Study. Turk J Orthod 2020; 33(2): 110-4.

\section{ABSTRACT}

Objective: This study aimed to compare the effects of passive self-ligating (PSL) and conventional ligating (CL) of brackets on the buccolingual inclination (BLINC) of the maxillary premolars.

Methods: This in vitro study included a PSL bracket group and a CL bracket group. Acrylic teeth on typodonts were aligned using 0.014-inch heat-activated nickel titanium (HANT) (T1) and $0.019 \times 0.025$-inch HANT (T2) and $0.021 \times 0.025$-inch stainless steel (SS) (T3) archwires in a sequence. Standardized cone beam computed tomography (CBCT) images were taken immediately after each archwire stage. The differences of premolar teeth BLINC values in the $0.019 \times 0.025$-inch and 0.014-inch HANT archwires (T2-T1) and $0.021 \times 0.025$-inch SS and 0.019×0.025-inch HANT archwires (T3-T2) were compared between PSL and CL groups. The value of $p<0.05$ was considered statistically significant.

Results: The BLINC change of the second premolar (SPM) showed a statistically significant difference ( $p=0.008)$, but the BLINC change of the first premolar (FPM) $(p=0.056)$ between the groups showed no statistically significant difference during the T2T1 stage. However, there were statistically significant differences between two groups in the BLINC of the FPM $(p=0.032)$ and SPM $(p=0.032)$ in the T3-T2 stage. The angular changes in the buccal direction in the PSL group were higher than those in the CL group.

Conclusion: The PSL upper premolar brackets used with the $0.021 \times 0.025$-inch SS archwire produced more buccal crown movement of the upper PM teeth compared with that of the CL brackets.

Keywords: Cone beam computed tomography (CBCT), orthodontic brackets, premolar inclination

Main points:

This in vitro CBCT study aims to compare the effects of PSL and CL brackets on the BLINC of upper premolars.

In this study, a new method with reference points in the apex and buccal tubercle tips was used to investigate the BLINC of upper premonlars.

PSL upper premolar brackets used with a $0.021 \times 0.025$-inch stainless steel archwire produced more buccal crown movement of the upper premolar teeth compared to that of the $\mathrm{CL}$ brackets.

\section{INTRODUCTION}

Orthodontists attempt to properly position the teeth in order to ensure a stable, functional, and aesthetic occlusion. To achieve this treatment goal, the in-out, tip, and torque features must be efficiently expressed by the bracket archwire combinations (1). The change in the labiolingual inclination of a tooth is defined as the torque expression. The wire torque stiffness, the wire size, the bracket slot size, and the mode of ligation affect the torque expression (2-7). In orthodontic literature, most studies used various methods to investigate the torque expression of different bracket systems. These methods included orthodontic measurements and simulation system, finite-element method, radiographs, optical image correlation technique and custom test apparatuse, and cone beam computed tomography (CBCT) records (8-13). CBCT records were used to measure the labiolingual inclination and tip and apex movements of maxillary teeth because three-dimensional (3D) records are crucial to the optimal assessment of the root $(8,14)$.

Address for Correspondence: Sabahat Yazıcıoğlu, Department of Orthodontics, School of Dentistry Ondokuz Mayıs University, Samsun, Turkey E-mail: dtsabahat@hotmail.com

(C) Copyright 2020 by Turkish Orthodontic Society - Available online at turkjorthod.org
Received: September 11, 2019 Accepted: February 20, 2020 Available Online Date: May 22, 2020 
Previous studies on torque measurements have reported the effects of different brackets on incisor inclinations (15-17). However, no study has examined the effects of upper passive self-ligating (PSL) brackets on premolar inclination. Therefore, this in vitro CBCT study aims to compare the effects of PSL and conventional ligating (CL) upper premolar brackets on the buccolingual inclination (BLINC) of these premolars.

\section{METHODS}

The study consisted of a PSL bracket (SmartClip SL3, 3M Unitek, Monrovia, CA, USA) and a CL bracket (Gemini; 3M Unitek, Monrovia, CA, USA) with the same torque values. Conventional nonconvertible upper first molar tubes (3M Unitek) were used. Each bracket had 0.022 -inch slots. Table 1 provides information on the brackets. The centers of the clinical crowns were marked, and all upper incisor, canine, and premolar brackets were bonded at a standard height on the acrylic teeth by the same researcher (SY). Class II division 1 occlusion typodonts (Nissin, Kyoto, Japan) with 12 acrylic maxillary teeth (6+6) (Nissin) were used in this in vitro study. Before the teeth were seated in wax, slots of equal size were drilled on the apex and buccal tubercle tips with diamond ball bur. Australian wire of 0.014-inch diameter were bonded to these slots and used as reference points. This made it possible to distinguish the movement of teeth using CBCT imaging (Figure 1). One typodont model was prepared for each group. Ethical approval was not obtained because no patient material was used in this study.

The sample size was determined as per the method described by Katsikogianni et al. (18); five repetitions in each group with $95 \%$ confidence interval, $100 \%$ test power, and $\mathrm{f}=9.257$ effect size. The teeth were aligned using 0.014-inch heat-activated nickel titanium (HANT) archwires (3M Unitek, Monrovia, CA, USA) (T1), 0.019 $\times 0.025$-inch HANT archwires (3M Unitek, Monrovia, CA, USA) (T2), and $0.021 \times 0.025$-inch SS archwires (3M Unitek, Monrovia, CA, USA) (T3) in a sequence. A vinyl polysiloxane impression (Zhermack, Badia Polesine RO, Italy) was made just before each archwire application (T1, T2, T3) and used as records of previous maxillary arch forms (19). The typodonts were submerged in $45^{\circ} \mathrm{C}$ water for 30 minutes during each archwire stage. Five repetitions were performed with five different archwires for every archwire stage. After

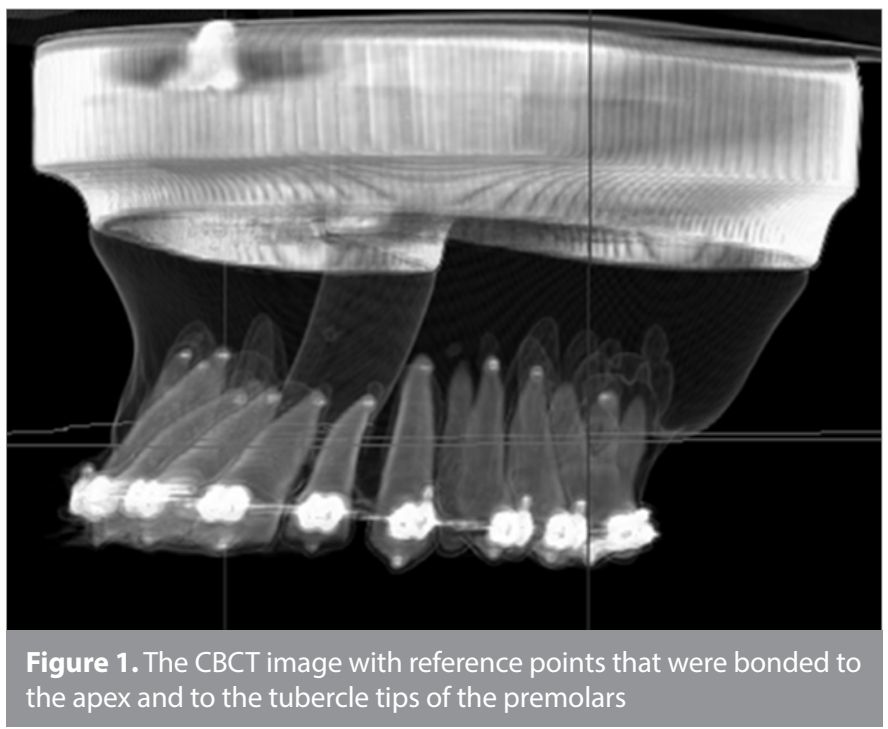

each archwire was removed, the impression was used to reposition the dentition. A total of 30 bracket-archwire combinations-15 for each group-were tested. With the CL brackets, the archwires were ligated with SS ligatures. The ligature wires were tightened and adjusted so that the wire could be pressed into the slot.

To capture the positional changes of maxillary teeth, standardized CBCT images were taken immediately after the 0.014inch HANT archwires, $0.019 \times 0.025$-inch HANT archwires, and $0.021 \times 0.025$-inch SS archwires were aligned with the maxillary teeth. A total of $30 \mathrm{CBCT}$ measurements were taken.

The CBCT images were captured using a GALILEOS Comfort PLUS CMCT unit (Sirona Dental Systems Inc., Bensheim, Germany). The settings were as follows: $98 \mathrm{kVp}, 25 \mathrm{mAs}$, 15.4-cm spherical imaging volume field of view, 14-second exposure time, and $0.25 \mathrm{~mm}$ isotropic voxel size. Changes in the BLINCs of premolars were measured using the Sidexis XG software package and the Galaxis 3D Viewer (Bensheim, Germany) on CBCT.

To measure the movement of the upper premolar teeth, reference planes were created on cross-sectional profiles of the CBCT images. The long axis of FPM was created between the tooth buccal tip and the buccal apex. The long axis of SPM, created between the tooth buccal tip and the apex, served as a reference for particular degrees of tilt. The angle between the long axis of each tooth and horizontal reference plane of the program used was measured (Figure 2).

\section{Statistical Analysis}

The data were analyzed using the Statistical Package for Social Sciences version 23.0 software (IBM Corp.; Armonk, NY, USA). Compliance with a normal distribution was analyzed using the Shapiro-Wilk test (Table 2). The measurements taken after each archwire application for each bracket system have been presented as median (min-max). Changes in BLINCs of the upper premolar teeth were measured for the 14-inch HANT (T1) and $0.019 \times 0.025$-inch HANT (T2) archwires, as well as for the $0.019 \times 0.025$-inch HANT (T2) and $0.021 \times 0.025$-inch SS (T3) archwires. Intergroup differences were evaluated using the Mann-Whitney $U$ test. The value $p<0.05$ was considered as statistically significant.
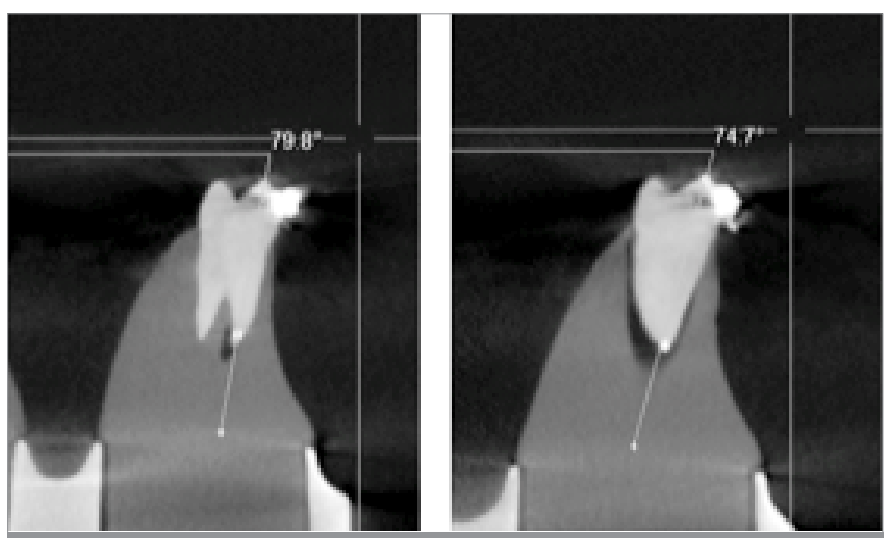

Figure 2. The angle between the long axis of the first and second premolars and the horizontal reference plane, respectively. 
Table 1. The prescriptions of the brackets in this study

$\begin{array}{lccccc}\text { Tooth } & \text { Bracket group } & \text { Slot width (inch) } & \text { Torque }\left(^{\circ} \text { ) }\right. & \text { Angulation }\left({ }^{\circ} \text { ) }\right. & \text { In/Out (inch) } \\ \text { FPM } & \text { PSL } & 0.022 & -7 & 0 & 0.036 \\ & \mathrm{CL} & 0.022 & -7 & 0 & 0.030 \\ \text { SPM } & \mathrm{PSL} & 0.022 & -7 & 0 & 0.036 \\ & \mathrm{CL} & 0.022 & -7 & 0 & 0.040 \\ \text { FPM: first premolar; SPM: second premolar; PSL: passive self-ligating; CL: conventionally ligating }\end{array}$

\begin{tabular}{|c|c|c|c|c|c|}
\hline Bracket group & Time & Tooth & Test statistics & SD & $\mathbf{p}$ \\
\hline \multirow[t]{3}{*}{ PSL } & $\mathrm{T} 1$ & FPM & 0.884 & 5 & 0.326 \\
\hline & $\mathrm{T} 2$ & FPM & 0.799 & 5 & 0.079 \\
\hline & & SPM & 0.948 & 5 & 0.725 \\
\hline \multirow[t]{4}{*}{$\mathrm{CL}$} & $\mathrm{T} 1$ & FPM & 0.845 & 5 & 0.179 \\
\hline & & SPM & 0.778 & 5 & 0.075 \\
\hline & $\mathrm{T} 2$ & FPM & 0.798 & 5 & 0.078 \\
\hline & & SPM & 0.817 & 5 & 0.111 \\
\hline
\end{tabular}

Table 3. Comparison of the differences in BLINC between different bracket groups with Mann Whithey U test

\begin{tabular}{|c|c|c|c|c|c|c|}
\hline \multirow[b]{2}{*}{ Tooth } & \multicolumn{2}{|c|}{$\begin{array}{c}\text { T2-T1 } \\
\text { Median (min: } \max )\end{array}$} & \multirow[b]{2}{*}{$\mathbf{p}$} & \multicolumn{2}{|c|}{$\begin{array}{c}\text { T3-T2 } \\
\text { Median (min: max) }\end{array}$} & \multirow[b]{2}{*}{$\mathbf{p}$} \\
\hline & PSL & $\mathrm{CL}$ & & PSL & CL & \\
\hline SPM BLINC $\left({ }^{\circ}\right)$ & $-0,5(-3,3: 0)$ & $1,3(1: 2,3)$ & 0,008 & $-2,1(-3,7:-0,5)$ & $-0,5(-1,8: 0,8)$ & 0,032 \\
\hline
\end{tabular}

The measurement errors were calculated using the Dahlberg formula $\left(\mathrm{Se}=\sqrt{\Sigma} \mathrm{d}^{2} / 2 \mathrm{n}\right)$, with $0.87^{\circ}$ for angular measurements.

\section{RESULTS}

The differences of premolar teeth BLINC values in the $0.019 \times 0.025$-inch and 0.014-inch HANT archwires (T2-T1) and $0.021 \times 0.025$-inch SS and $0.019 \times 0.025$-inch HANT archwires (T3T2) were compared among PSL and $\mathrm{CL}$ groups. The results have been presented in Table 3.

The BLINC change of the second premolar (SPM) showed statistically significant difference $(p=0.008)$, but the BLINC change of the first premolar (FPM) $(p=0.056)$ showed no statistically significant difference between the groups during the T2-T1 stage. There were statistically significant inter-group differences in BLINC of the FPM $(p=0.032)$ and SPM $(p=0.032)$ in the T3-T2 stage.

\section{DISCUSSION}

In this experimental study, we used 0.014-inch HANT, $0.019 \times 0.025$-inch HANT, and $0.021 \times 0.025$-inch SS archwires. Although $0.021 \times 0.025$-inch SS archwire is not routinely used in clinical practice, this archwire reflects the torque values of the brackets better because the engagement angle decreased by $6^{\circ}$ when a $0.021 \times 0.025$-inch SS archwire was used $(3,20)$. According to Alexander, $5^{\circ}$ of effective torque were lost with every 0.001 inch gap between the vertical slot and the archwire (21).

In the PSL group, in the T2-T1 stage, while the SPM was angled in the buccal direction, the FPM showed angulation in palatinal direction parallel to the torque value of the bracket. In the T3-T2 stage, the BLINC changes of the FPM and SPM were in the buccal direction. The angular changes in the PSL group were statistically significantly higher than those in the CL group. It has been suggested that this angulation is formed in the opposite direction according to the torque value of the bracket. This may be caused by the deterioration of the relationship with the slot base and archwire as the posterior tooth sequence goes distally and as the stiffness of the archwire increases. In the CL group, in the T2-T1 stage, although the BLINCs of the FPMs and SPMs changed in the palatinal direction, in the T3-T2 stage, the fact that the SPM was opened in the buccal direction also supports this view. The $\mathrm{CL}$ premolar brackets were more compatible with the torque value of the brackets than the PSL brackets, particularly in the T2-T1 stage. This can be explained by the ligation form of the premolar brackets. The compression fit- 
ting of the SS ligatures used with the CL brackets may have resulted in the archwire better fitting into the slot. Fischer-Brandies et al. (6) also reported that using SS ligatures decreased the clearance between the slot and archwire, even with space between them. Al-Thomali et al. (22) concluded that CL brackets had higher torque expression than self-ligating brackets. Huang et al. (10) reported that self-ligating Damon and Speed brackets had lower torque capabilities compared to those of conventional Discovery brackets. In contrast, Katsikogianni et al. (18) reported that CL brackets had lower torque capabilities than those of the self-ligating brackets. According to Yeh et al. (23), torque control in PSL brackets was similar to that in the CL brackets. Fleming et al. (24) were reported that no significant differences were found in the inclination changes of the molar and incisor between the CL brackets and either active or passive SL. Lineberger et al. (25) reported no significant changes on crown torque for any teeth, with the exception of maxillary premolars, which showed a significant increase on the buccal crown torque in a PSL system.

In orthodontic treatment, clinical and physiological factors may cause a variety of clinical responses to a bracket archwire combination. Therefore, this in vitro study cannot fully represent a clinical reality. The findings of this study may be supported or rejected by the findings of future clinical studies on the inclination effects of various bracket archwire combinations.

\section{CONCLUSION}

Based on the findings of this in vitro study, PSL upper premolar brackets used with a $0.021 \times 0.025$-inch SS archwire produced more buccal crown movement of the upper premolar teeth compared to that of the $C L$ brackets.

Ethics Committee Approval: Ethical approval was not obtained because no patient material was used in this in vitro study.

\section{Informed Consent: N/A.}

Peer-review: Externally peer-reviewed.

Author Contributions: Conception - S.Y.; Design - S.Y., S.A., M.Ö.; Supervision - S.A., M.Ö.; Data Collection and/or Processing - S.Y., A.A.Ö., N.A.; Analysis and/or Interpretation - A.Z.Ö., N.A.; Writing Manuscript - S.Y., A.A.Ö., A.Z.Ö.; Critical Review - S.A., M.Ö.; Literature Search A.Z.Ö., A.A.Ö., N.A.

Conflict of Interest: The authors declare that they have no conflict of interest.

Financial Disclosure: This study was supported by Ondokuz Mayıs University Project Management Office (Project number: PYO. DIS.1901.13.006).

Acknowledgement: The authors thank to Dr. Semiha Arslan for her assistance in the obtaining of $\mathrm{CBCT}$ records.

\section{REFERENCES}

1. McLaughlin RP, Bennett JC, Trevisi HJ. Systemized orthodontic treatment mechanics. Elsevier Health Sciences; 2001.
2. Morina E, Eliades T, Pandis N, Jäger A, Bourauel C. Torque expression of self-ligating brackets compared with conventional metallic, ce $\neg$ ramic, and plastic brackets. European J Orthod 2008; 30: 233-8. [Crossref]

3. Archambault A, Lacoursiere R, Badawi H, Major PW, Carey J, FloresMir C. Torque expression in stainless steel orthodontic brackets. A systematic review. Angle Orthod 2010; 80: 201-10. [Crossref]

4. Joch A, Pichelmayer M, Weiland F. Bracket slot and archwire dimensions: manufacturing precision and third order clearance. J Orthod 2010; 37: 241-9. [Crossref]

5. Cash AC, Good SA, Curtis RV, McDonald F. An evaluation of slot in orthodontic brackets - are standards as expected? Angle Orthod 2004; 74: 450-3.

6. Fischer-Brandies H, Orthuber W, Es-Souni M, Meyer S. Torque transmission between square wire and bracket as a function of measurement, form and hardness parameters. J Orofac Orthop 2000; 61: 258-65. [Crossref]

7. Harzer W, Bourauel C, Gmyrek H. Torque capacity of metal and polycarbonatebrackets with and without a metal slot. Eur J Orthod 2004; 26: 435-41. [Crossref]

8. Lee RJ, Pham J, Choy M, Weissheimer A, Dougherty HL Jr, Sameshima GT, et al. Monitoring of typodont root movement via crown superimposition of single cone-beam computed tomography and consecutive intraoral scans. Am J Orthod Dentofacial Orthop 2014; 145: 399-409. [Crossref]

9. Li Y, Tang N, Xu Z, Feng X, Yang L, Zhao Z. Bidimensional techniques for stronger anterior torque control in extraction cases: A combined clinical and typodont study. Angle Orthod 2011; 82: 715-22. [Crossref]

10. Huang $Y$, Keilig L, Rahimi A, Reimann S, Eliades $T$, Jäger $A$, et al. Numeric modeling of torque capabilities of self-ligating and conventional brackets. Am J Orthod Dentofacial Orthop 2009; 136: 638-43. [Crossref]

11. Sangcharearn $Y$, Ho C. Effect of incisor angulation on overjet and overbite in class II camouflage treatment: A Typodont Study. Angle Orthod 2007; 77: 1011-8. [Crossref]

12. Lacoursiere RA, Nobes DS, Homeniuk DL, Carey JP, Badawi HH, Major PW. Measurement of orthodontic bracket tie wing elastic and plastic deformation by arch wire torque expression utilizing an optical image correlation technique. J Dent Biomechanics 2010; 1: 397037. [Crossref]

13. Sifakakis I, Pandis N, Makou M, Eliades T, Katsaros C, Bourauel C. Torque expression of 0.018 and 0.022 inch conventional brackets. Eur J Orthod 2013; 35: 610-14. [Crossref]

14. Tong H, Enciso R, Van Elslande D, Major PW, Sameshima GT. A new method to measure mesiodistal angulation and faciolingual inclination of each whole tooth with volumetric cone-beam computed tomography images. Am J Orthod Dentofacial Orthop 2012; 142: 133-43. [Crossref]

15. Isaacson RJ, Lindauer SJ, Rubenstein LK. Moments with the edgewise appliance: incisor torque control. Am J Orthod Dentofacial Orthop 1993; 103: 428-38. [Crossref]

16. Liang W, Rong Q, Lin J, Xu B. Torque control of the maxillary incisors in lingual and labial orthodontics: a 3-dimensional finite element analysis. Am J Orthod Dentofacial Orthop 2009; 135: 316-22. [Crossref]

17. Pandis N, Strigou S, Eliades T. Maxillary incisor torque with conventional and self-ligating brackets: a prospective clinical trial. Orthod Craniofac Res 2006; 9: 193-8. [Crossref]

18. Katsikogianni EN, Reimann S, Weber A, Karp J, Bourauel C. A comparative experimental investigation of torque capabilities induced by conventional and active, passive self-ligating brackets. Eur J Orthod 2014; 37: 440-6. [Crossref] 
19. Lia Y, Tangb N, Xub Z, Fengb X, Yangb L, Zhaoc Z. Bidimensional techniques for stronger anterior torque control in extraction cases: a combined clinical and typodont study. Angle Orthod 2012; 82: 715-22. [Crossref]

20. Badawi HM, Toogood RW, Carey JP, Heo G, Major PW. Torque expression of self-ligating brackets. Am J Orthod Dentofacial Orthop 2008; 133: 721-8. [Crossref]

21. Alexander R. The Alexander Discipline: The 20 Principles of the Alexander Discipline. Quintessence Publ. 2008.

22. Al-Thomali Y, Mohamed RN, Basha S. Torque expression in self-ligating orthodontic brackets and conventionally ligated brackets: a systematic review. J Clin Exp Dent 2017; 9: e123-8.
23. Yeh C-L, Kustano B, Viana G, Evans CA, Drummond JL. In-vitro evaluation of frictional resistance between brackets with passive-ligation designs. Am J Orthod Dentofacial Orthop 2007; 131: 704.e11-22. [Crossref]

24 Fleming PS, Lee RT, Marinho V, Johal A. Comparison of maxillary arch dimensional changes with passive and active self-ligation and conventional brackets in the permanent dentition: a multicenter, randomized controlled trial. Am J Orthod Dentofacial Orthop 2013; 144: 185-93. [Crossref]

25. Lineberger MB, Franchi L, Cevidanes LHS, Ghislanzoni LTH, McNamara $\mathrm{Jr} \mathrm{JA}$. Three-dimensional digital cast analysis of the effects produced by a passive selfligating system. Eur J Orthod 2016; 38: 609-14. [Crossref] 